\title{
Hesperopithecus, the Anthropoid Primate of Western Nebraska.
}

\section{By Prof. Henry Fairfield Osborn, American Museum of Natural History, New York.}

F VERY discovery directly or indirectly relating E. to the pre-history of man attracts world-wide attention and is apt to be received either with too great optimism or with too great incredulity. One of my friends, Prof. G. Elliot Smith, has perhaps shown too great optimism in his most interesting newspaper and magazine articles on Hesperopithecus, while another of my friends, Dr. A. Smith Woodward, has shown too great incredulity in his article in NATURE of June Io. It is in reply to both these extremes that I have especially prepared for NATURE additional information regarding the fauna and habitat of this new Primate, and additional figures to show the comparison between
Book of Job (xii. 8), "Speak to the earth and it shall teach thee." In brief, I advised Mr. Bryan to drop all his books, as well as his attempts to grasp the meaning of the diversity of opinion among scientific writers, and to inquire of the earth only what it had to teach him. I added that he would not necessarily lose his religion, but that he. would certainly become an evolutionist.

I presume it is widely known that Mr. Bryan is a native and prominent citizen of the State of Nebraska, and it is certainly a humorous coincidence that on March I4, only nine days after my advice was given, I received from the western part of the State of Nebraska the tooth from which has been named the

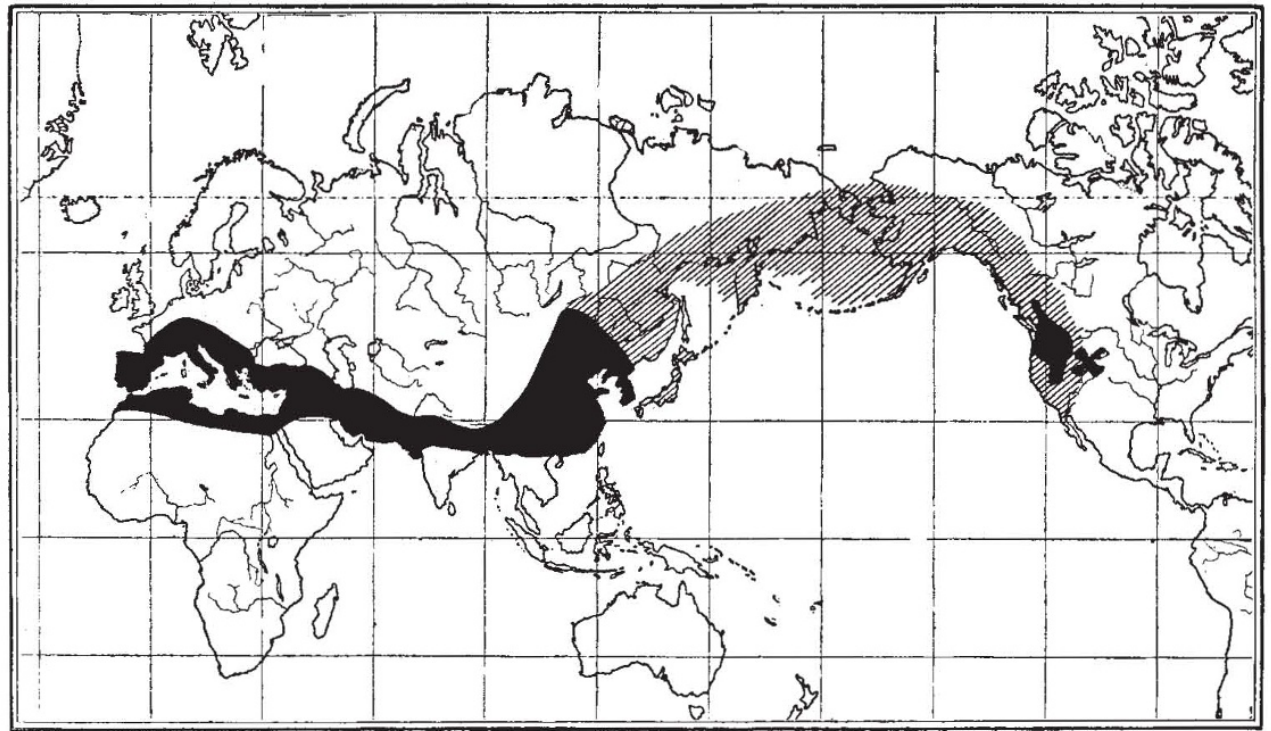

FIG. I.-Upper Miocene and Pliocene distribution of the Strepsicerine and Hippotragine Antelopes. Known distribution inck hypothetical migration area in oblique lines.

$\mathrm{X}$, Region of western Nebraska, Snake Creek beds, site of the discovery of the Hesperopithecus tooth.

the small, water-worn, type tooth of the genus (Fig. 2, I-4) and the teeth which most nearly resemble it.

First, a word regarding the time and circumstances of the discovery of this Primate which happen to have a humorous side. Fresh and very violent attacks on the Darwinian theory have been made during the last two or three years all over the United States, especially under the leadership of William Jennings Bryan, a man of ingenious and fertile mind and persuasive powers of oratory, gifted as a politician and as a religious advocate. As an opponent to Darwinism, Mr. Bryan's attack culminated in his very carefully prepared article in the New York Times of Sunday, February 26, I922, in which he ably fortified his position by long quotations from Prof. W. Bateson's Toronto address recently published in NATURE (April 29, p. 553), and by other critics of Darwinism. The following Sunday, March 5, I replied to $\mathrm{Mr}$. Bryan, and realising that quotations from the highest scientific authorities in the world would not have the slightest influence upon him or his followers I referred him to the writings of St. Augustine, also to the Holy Scriptures, and especially to a passage in the
Ape of the Western World (Hespusopithecus). This is the very first evidence, after seventy-five years of continuous search in all parts of our great western territory, of a Primate of any kind above the ranks of the numerous Lemur - like and Tarsius - like lower Primates which have long been known in our Eocene beds.

While we have all eagerly looked forward to such a discovery, and I have always regarded it as possible, I have never regarded it as probable, for the reason that the higher Primates, seeking the protection of forests, never venture out for long distances on the plains; moreover, accustomed to a forest fruit supply, they would have been exposed to great dangers in migrating from Asia to western North America except by the aid of a continuous forest belt or of a rather dense forest and savanna belt bordering a plains belt. In I9ro I published in my "Age of Mammals" (page 336, Fig. I56) a map, which I now send to NATURE for reproduction (Fig. I), with indications of such a life belt for animals of the plains-antelopes and horses ; adding an $\mathrm{X}$ to show where Hesperopithecus was found. 
Since rgro additional discoveries have been made which tend to indicate the existence also of a continuous forest and savanna belt between eastern Asia and western North America (black area and oblique lines), for we have found animals related to the strepsicerine and hippotragine antelopes, to the plains ungulates remotely related to the kudu, to the sable antelope, and to the eland (Taurotragus). We have also traced the migration of two kinds of forest- and savannaliving mastodons over this entire region, namely: (I) of proboscideans closely related to the $M$. arvernensis of southern Europe, to the $M$. sivalensis of India, and to the $M$. mirificus of western Nebraska, specimens of which have now been found in the very Snake Creek three kinds of antelopes and of the two kinds of mastodons above mentioned. Finally, of the utmost rarity are the remains of the Primates, because during the eight seasons of continuous and expert search we have only discovered two teeth, namely, the tooth now regarded as a third superior molar of an old individual of Hesperopithecus found by Dr. W. D. Matthew in I908, and the type tooth of Hesperopithecus haroldcookii found by the geologist Harold J. Cook in r92I. We are this season renewing the search with great vigour and expect to run every shovelful of loose river sand which composes this deposit through a sieve of mesh fine enough to arrest such small objects as these teeth. Even by this most laborious and painstaking method
the probability of finding more
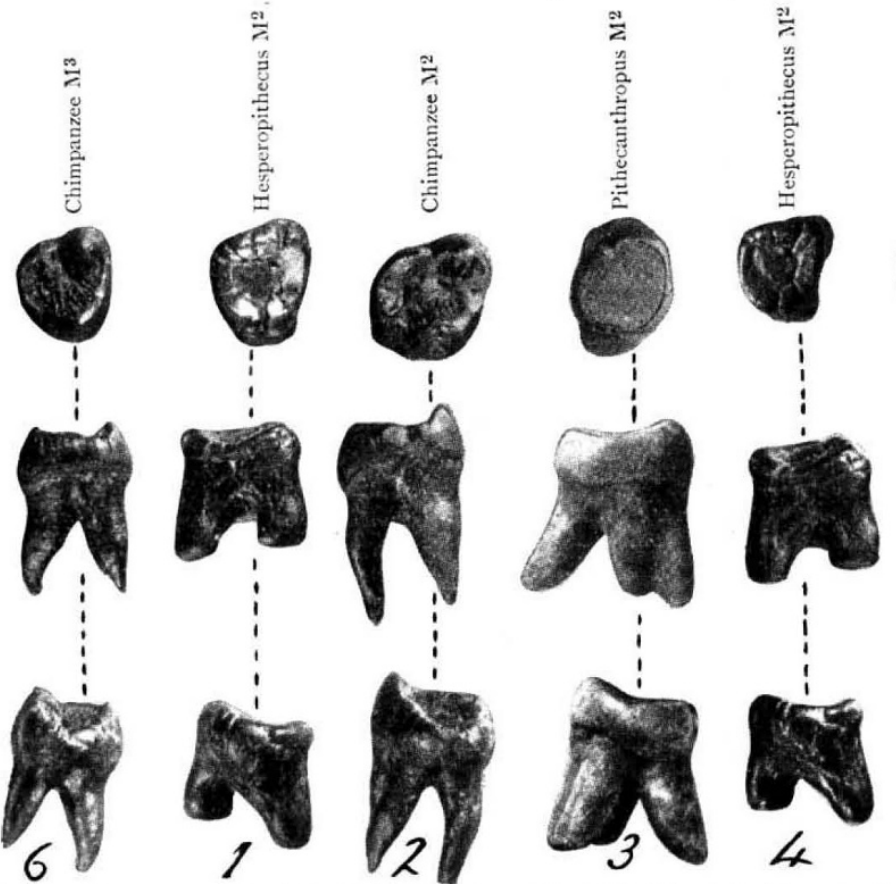

material is not very great, for the reason that the anthropoid Primates have always been very clever and resourceful animals, climbing into trees in times of flood, avoiding the low sandy levels and watercourses where ungulates are trapped.

Before re-examining the new figures (Fig. 2) of the Hesperopithecus tooth, may I quote verbally, with some unessential omissions, my own original characterisation of the tooth, for which I alone am responsible.

This second upper molar tooth is very distant from the gorilla type, from the gibbon type, from the orang type; among existing anthropoid apes it is nearest to $m^{2}$ of the chimpanzee, but the resemblance is still very remote. . . Thus the proportions of the molar crown of the Hesperopithecus type are about the same as those in the Homo sapiens mongo. loideus type. There is also a distant human resemblance in the molar pattern of Hesperopithecus ... to the low, basin-shaped, channelled crown in certain examples of Homo sapiens. But the Hesperopithecus molar cannot be said to resemble any known type of human molar very closely. The author agrees with Mr. Cook, with Dr. Hellman, and with Dr. Gregory, that it resembles the human type more closely than it does

any known anthropoid ape type;

beds in which Hesperopithecus was discovered; also (2) of the true forest-living proboscideans of the genus Mastodon recently recognised in the Snake Creek beds. A true elephant (E. hayi), which resembles the Elephas planifrons of the Upper Siwaliks of India, has been found in more recent deposits.

From these relatively new and most significant discoveries we may characterise the Snake Creek region of western Nebraska, in Middle Pliocene time, as in the belt of the south Asiatic forest, savanna, and plains fauna, which extends two-thirds of the way around the entire globe, from the region of Britain to the centralwest region of the United States, and probably right across to the Atlantic coast. The plains element in this fauna is extremely abundant, especially the Hipparion; somewhat more rare are the true horses (Pliohippus), and still more rare are the remains of the a new and independent type of Primate and ve' must seek more material before we can determine its relationships. It is certainly not closely related to Pithecanthropus evectus in the structure of the crown, for Pithecanthropus has a single, contracted crown in which the superior grinding surface has a limited crenulated basin, whereas Hesperopithecus has a widely open crown with broadly channelled or furrowed margins, and a postero-internal crest suggesting the hypocone of a higher Primate form. ...

The type description, as published in the American Museum Novitates, April 25, I922, requires little or no modification as a result of two months of intensive research which has been devoted to this tooth, detailed results of which will shortly be published by my colleague, Prof. Gregory. The accompany* ing new illustrations (Fig. 2), prepared especially consequently, it would be misleading to speak of this
Hesperopithecus at present as an anthropoid ape 
for NATURE, are photographs of a most convincing character, in which the Hesperopithecus molar (Fig. 2, $\mathrm{I}-4)$, in three aspects, is placed directly between corresponding molars of a chimpanzee (right and left) which most nearly resemble it. It will be seen at once (r) that the Hesperopithecus molar, althougn greatly water-worn, has entirely different proportions from the chimpanzee molar: it is much broader transversely; it is much narrower in the fore-and-aft dimensions. This affords positive evidence that Hesperopithecus had a shorter facial region than the chimpanzee. In this respect it approaches the mongoloid human type (Fig. 2, 5) more closely than it does any of the anthropoid ape types; (2) the roots of the Hesperopithecus molar are much more robust and more human in proportion than those of any of the frugivorous apes; (3) the upper molar of Hesperopithecus, while resembling the upper molars of certain American Indians of mongoloid type in several absolute measurements, differs widely in the more asymmetrical form of the crown, which is broader in front and narrower behind, whereas in the mongoloid human molars the crown is more symmetrical; (4) the type upper molar of Hesperopithecus differs from the corresponding molar in the Trinil Ape-man (Pithecanthropus) (Fig. 2, 3) in nearly all its absolute measurements ; but it resembles the Pithecanthropus molar in the great size of the internal (lingual) fang, also in the wide separation of the internal (lingual) and external (anterobuccal) fangs. It also resembles Pithecanthropus in the evenly concave depression of the grinding surface, which is quite unlike the ridged form of the grinding surface observed in a chimpanzee molar (Fig. 2, 2-6) ; (5) as for the comparison suggested by Dr. Smith Woodward with the third lower molar of the Pliocene bear (Hyænarctos), the differences are so fundamental that it is difficult to find any single point of agreement; the molar of Hesperopithecus very clearly conforms to the flattened tritubercular to quadritubercular type which characterises all the upper molars of anthropoid apes and of man.

Thus, after making due allowance for the characters resulting from the prolonged natural usage of the Hesperopithecus molar, also for characters due to long exposure to erosion and stream action, and to percussion by the sharp sand of the river bed, there nevertheless remain five outstanding sharacters, as well as many highly significant details of character, which tend to show that this tooth belongs to one of the higher Primates, and that this genus ultimately may be included either within the Simiidæ (anthropoid apes), or near certain ancestors of the Hominidæ (human stock).

I desire to summarise with emphasis my original statements about this tooth, namely, that among existing anthropoid apes it is nearest to $m^{2}$ of the chimpanzee, but the resemblance is still very remote ... that the proportions of the molar crown of Hesperopithecus are about the same as in Homo sapiens mongoloideus (American Indian) type . . . that there is also a distant human resemblance in the molar pattern of Hesperopithecus to the low, basin-shaped, channelled crown in certain examples of Homo sapiens... that the Hesperopithecus molar cannot be said to resemble any known type of human molar very closely. It is certainly not closely related to Pithecanthropus erectus in the structure of the molar crown ... it is therefore a new and independent type of Primate, and we must seek more material before we can determine its relationships.

My original characterisation and description have been fully confirmed by the intensive research of the past two months. I have not stated that Hesperopithecus was either an Ape-man or in the direct line of human ancestry, because I consider it quite possible that we may discover anthropoid apes (Simiidæ) with teeth closely imitating those of man (Hominidæ), just as we have discovered in the true Piltdown man (Eoanthropus) teeth closely imitating those of the chimpanzee. There are so many crisscross adaptations of this kind among the mammals that we can never be sure about the family relationships of an animal until we secure not only the teeth but considerable parts of the skeleton as well. No anatomist in the possession of Pithecanthropus molars only would have discovered the human resemblance which is indubitably established by the roof of the cranium, by the shape of the brain, and by the shape of the thigh bone. For similar skeletal parts of Hesperopithecus we are making most determined and prolonged search in the type locality; it is not at all probable that the desired evidence will be easy to secure. Until we secure more of the dentition, or parts of the skull or of the skeleton, we cannot be certain whether Hesperopithecus is a member of the Simiidæ or of the Hominidæ.

\section{Science in Egypt.}

\section{By Col. H. G. Lyons, F.R.S.}

THE important part which modern science can play in the economical development of natural resources is generally recognised to-day, but nowhere may this be seen more clearly than in Egypt, with its subtropical climate, its controlled water-supply, and its immunity from the vagaries of the weather which affect more northern latitudes. Here a population which in $\mathrm{I} 882$ was under seven millions has now grown to more than twelve millions, and inhabits a cultivable area which does not exceed seven million acres all intensively cultivated; for much of the area, which was formerly flooded annually and then furnished a single crop after the river had fallen, is now under perennial cultivation with a supply of water at all seasons, and consequently up to five crops in two years are taken from it. Under these conditions the most economical use of the material resources that science can devise, and all the improvements that it can suggest, are of the utmost importance to the country.

During Egypt's period of financial difficulty the provision for scientific work was very meagre, but with the reorganisation of the irrigation and the introduction of reforms, an improving revenue enabled gradually increasing grants to be made to state departments, and many of them have, during the past thirty years, established services in which scientific work of value and importance has been carried on.

Some scientific work had been initiated at a much 